\title{
The neglected role of stewardship in strategic purchasing of health services: who should buy?
}

\author{
Djavad Ghoddoosi Nejad ${ }^{1}$, Ali Janati ${ }^{2}$ and Morteza Arab-Zozani ${ }^{2,3}$
}

${ }^{1}$ Social Determinants of Health Research Center, Department of public health, Faculty of health, Birjand University of Medical Sciences, Birjand, Islamic Republic of Iran. ${ }^{2}$ Iranian Center of Excellence in Health Management, School of Management and Medical Informatics, Tabriz University of Medical Sciences, Tabriz, Islamic Republic of Iran. (Correspondence to: Morteza Arab-Zozani: arab.hta@gmail.com). ${ }^{3}$ Student Research Committee, Tabriz University of Medical Sciences, Tabriz, Islamic Republic of Iran.

Citation: Ghoddoosi Nejad D; Janati A; Arab-Zozani M. The neglected role of stewardship in strategic purchasing of health services: who should buy? East Mediterr Health J. 2018;24(11):1038-1039. https://doi.org/10.26719/2018.24.11.1038

Received: 26/11/17; accepted: 28/06/18

Copyright (c) World Health Organization (WHO) 2018. Some rights reserved. This work is available under the CC BY-NC-SA 3.o IGO license (https:// creativecommons.org/licenses/by-nc-sa/3.o/igo).

Sir,

The World Health Organization (WHO) introduced a framework to evaluate performance of every health system in its World Heath Report 2000 (1). This framework includes three goals: good health, financial protection against healthcare costs, and responsiveness to nonmedical needs. In order to achieve these goals four functions have been outlined: 1) resources creation and generation; 2) financing; 3) service delivery; and 4) stewardship of health system (1). The financing function consists of three sub-functions; revenue collection, pooling, and purchasing. Based on this function, it is recommended that strategic purchasing should be used instead of inactive (passive) purchasing $(1,2)$.

As defined by WHO, strategic purchasing implies a continuous search for finding means to taking maximum advantage of the lowest cost and resources in order to reach cost-effectiveness in a health system. Strategic purchasing can be ensured by responding correctly and precisely to five classical questions: what should we buy? From whom should we buy? At what price should we buy? How should we buy? For whom should we buy the interventions? (1). In fact, strategic purchasing of healthcare services/interventions is fundamental to the holistic reform in a health care system, which involves all stakeholders. Therefore, clarity in the roles of purchaser/ purchasers and other actors is very important (3).

In this regard, since most low- and middle-income countries use a "public assistance system" for an array of healthcare operations, there is no unique defined organization to handle the stewardship and to organize and manage purchaser/purchasers (4). In fact, in lowand middle-income countries that have experienced some level of strategic purchasing of healthcare services
(5), severe stewardship challenges can be found (3). In Cambodia (2), Kenya (6) and the Islamic Republic of Iran $(3,7)$, lack of well-defined duties, roles and legislation is obvious. In aggregate, it is not clear "who should buy" the interventions.

The answer to this question is, in fact, the "sixth dimension" of successful strategic purchasing. Failure to answer this question leads to complications for the health system such as: fragmentation, wastage of resources, parallel works, conflict of interest, and finally, failure in obtaining potential benefits of strategic purchasing of health services.

According to the principles of the economic market, purchaser/provider split reform was developed to give economic incentives to both providers and purchasers (8). Health systems use tools and approaches such as licensing, accreditation, full recognition and classification of mechanisms to manage health services providers. From the other side, it is also advisable to identify purchasers and their financial strengths, and design and implement a mechanism for their licensing, validation and accreditation. This will ensure provision of health services as a result of a suitable contract between purchasers and providers in order to optimize patients' outcomes and costs of health services, and forms a perquisite for good stewardship in every health system.

Regarding the above mentioned factors, it may be suggested that before implementing strategic purchasing in a health context, the structure of healthcare system stewardship should be reviewed and strengthened. If stewardship perquisites of strategic purchasing are ensured (including robust and accurate intelligence for policy and regulation generation) (1), and a rigorous and clear answer to "who should buy" can be provided, then the health system can accurately position itself to answer the five classical questions.

\section{References}

1. World Health Organization. The world health report 2000: health systems: improving performance. Geneva: World Health Organization; 2000. 
2. Bigdeli M, Annear PL. Barriers to access and the purchasing function of health equity funds: lessons from Cambodia. Bull World Health Organ. 2009;87(7):560-4. http://dx.doi.org/10.2471/BLT.08.053058

3. Janati A, Nejad DG, Doshmangir L, Imani A. Challenges of Implementing Strategic Purchasing Of Health Services in Iran: A Qualitative Study. Acta Med Mediter. 2016;32:1033-8.

4. Preker AS. Public ends, private means: strategic purchasing of health services. Washington, DC: World Bank Publications; 2007. http://dx.doi.org/10.1596/978-0-8213-6547-2

5. Ghoddoosi-Nezhad D, Janati A, Arab-Zozani M, Doshmagir L, Sadeghi Bazargani H, Imani A. Is strategic purchasing the right strategy to improve a health system's performance? A systematic review. Bali Med J. 2017;6(1):102-13. http://dx.doi.org/10.15562/ bmj.v6ii.369

6. Munge K, Mulupi S, Barasa EW, Chuma J. A critical analysis of purchasing arrangements in Kenya: the case of the National Hospital Insurance Fund. Int J Health Policy Manag. 2017 Mar;7(3):244-54. http://dx.doi.org/10.15171/ijhpm.2017.81

7. Ghoddoosi-Nejad D, Jannati A, Doshmangir L, Arab-Zozani M, Imani A. Stewardship as a fundamental challenge in strategic purchasing of health services: a case study of Iran. Value in health regional issues. 2019 May;18:54-8. https://doi.org/10.1016/j. vhri.2018.06.005.

8. Tynkkynen LK, Keskimäki I, Lehto J. Purchaser-provider splits in health care-The case of Finland. Health Policy. 2013 Aug 1;111(3):221-5. http://dx.doi.org/10.1016/j.healthpol.2013.05.012 